\title{
ESTÁGIO SUPERVISIONADO NA FORMAÇÃO DO PROFESSOR DE HISTÓRIA: PERCEPÇÕES DE ALUNOS ESTAGIÁRIOS
}

\author{
SUPERVISED INTERNSHIP IN HISTORY TEACHER TRAINING: TRAINEE STUDENTS' PERCEPTIONS \\ PASANTÍAS SUPERVISADAS EN LA FORMACIÓN DE PROFESORES DE HISTORIA: PERCEPCIONES \\ DE ALUMNOS PASANTES
}

\begin{abstract}
Anelise Martinelli Borges de Oliveira
Professora Universidade Federal do Triângulo Mineiro (UFTM). Doutora em Educação pela Universidade Estadual Paulista Júlio de Mesquita Filho - UNESP - Campus Marília SP.

E-mail: anelisemartinelli@hotmail.com

Orcid: https://orcid.org/0000-0002-7953-6160
\end{abstract}

\begin{abstract}
RESUMO
O objetivo deste texto é refletir sobre o papel do Estágio Curricular Supervisionado no processo de formação do professor de História. Para tanto, seus objetos de análise são relatórios de estágio de alunos do curso de Licenciatura em História de uma universidade pública localizada em Minas Gerais. Tal análise se concentrou nos relatos acerca da autoavaliação, bem como nas experiências de observação e regência. Os resultados mostram que o estágio permitiu aos futuros professores/historiadores compreender o cotidiano escolar, refletir sobre o diálogo entre os conhecimentos históricos sistematizados pela historiografia e o processo do aprender a pensar historicamente, além de realizar intervenções que contribuíram para um ensino de História voltado à orientação prática da vida dos alunos.
\end{abstract}

Palavras-chave: Estágio supervisionado em História. Autoavaliação. Professor de História.

\section{ABSTRACT}

This text aims to reflect on the role of the Supervised Curricular Internship in the process of History teacher's formation. To do so, its objects of analysis are internship reports of History Degree Course students in a public university located in Minas Gerais. Such analysis focused on the reports about the self-evaluation, as well as the observation and the regency experiences. The results show that the internship allowed the future teachers/historians to understand the school daily life, to reflect on the dialogue between the historical knowledge systematized by historiography and the process of learning to think historically, as well as to carry out interventions that contributed to a History teaching aimed at students' practical life orientation.

Keywords: Supervised internship in History. Self-evaluation. History teacher.

\section{RESUMEN}

El propósito de este texto es reflexionar sobre el papel de la pasantía curricular supervisada en el proceso de formación docente de Historia. Para ello, su objeto de análisis son informes de pasantías de estudiantes de pregrado en Historia, de una universidad pública ubicada en Minas Gerais. Este análisis se centró en los informes de autoevaluación y en las experiencias de observación y práctica docente. Los resultados muestran que la pasantía permitió a futuros maestros / historiadores comprender la rutina escolar, reflexionar sobre el diálogo entre el conocimiento histórico sistematizado por la historiografía y el proceso de aprender a pensar históricamente, además de llevar a cabo intervenciones que contribuyeron a una enseñanza de la Historia dirigida a la orientación práctica de la vida de los estudiantes.

Palabras-clave: Pasantías supervisadas en Historia. Autoevaluación. Profesor de Historia. 


\section{INTRODUÇÃO}

Nos últimos anos, o tema formação de professores ganha destaque nas pesquisas acadêmico-científicas que tratam da indissociabilidade entre teoria e prática na construção da profissionalidade docente (FÁVERO, 2011; PIMENTA; LIMA, 2017). A formação inicial — e consequentemente o estágio - , requer um cuidado especial, por introduzir o licenciando no contexto do seu exercício profissional. Para além do conhecimento sobre métodos e técnicas de ensino, o processo de formação inicial precisa abarcar o desenvolvimento de habilidades inerentes a uma atuação social emancipadora.

O estágio supervisionado possibilita a criação de uma práxis educativa, porque o aprendizado torna-se mais eficiente quando é obtido por meio da experiência em sala de aula. Em um curso de licenciatura em História, é necessário considerar o processo de formação pessoal/profissional do historiador/docente, ao passo que deve ser possibilitado, quando de sua formação, o entendimento acerca do diálogo entre o conhecimento histórico sistematizado pela historiografia, e como este é apropriado, na escola, pelos alunos (RÜSEN, 2006).

Nesse sentido, o conhecimento assimilado na prática pode auxiliar o estagiário a refletir e a enfrentar situações cotidianas na escola, visto que aquele espaço é composto por sujeitos plurais. Ao discorrer sobre a forma de atuação do professor no contexto social atual, Cavalcanti (2003, p. 195) ressalta os seguintes aspectos:

[...] o processo de formação é de fato um processo de autoformação; a formação é um processo contínuo; a formação inicial e continuada tem como princípio a articulação ensino-pesquisa, ação-reflexão; o exercício da atividade profissional tem como base a reflexão crítica do professor. Outro elemento que tem sido considerado importante na formação do professor é o da construção da identidade profissional e seu papel nessa formação.

Para a construção da profissionalização docente, nota-se, portanto, a importância do diálogo entre universidade e escola.

Nessa perspectiva, o presente trabalho traz considerações sobre o papel do estágio curricular supervisionado no processo de formação do professor de História/historiador a partir de análise dos relatórios de estágio produzidos por graduandos de uma universidade pública mineira, cujos resultados serão contemplados. 


\section{Concepções de estágio supervisionado de um curso de licenciatura em História}

Enquanto campo de conhecimento, o estágio supervisionado se desenvolve na interação do curso de licenciatura com o espaço social, posto que envolve prática reflexiva e intervenção na vida cotidiana escolar.

Segundo Corsetti (2002), é primordial que os cursos de licenciatura ofereçam uma formação ampla, garantindo assim:

[...] o desenvolvimento não só da consciência social por parte dos futuros professores, mas também de sensibilidade social. Nesse sentido, é fundamental que os novos educadores possam ser preparados para que tenham a compreensão plena do papel da escolarização num mundo com o que atualmente se estrutura nos marcos de um processo de globalização (p. 35).

No que diz respeito ao curso de licenciatura em História, objeto do presente artigo, consta no Projeto Pedagógico que compete ao licenciando ser um profissional: “[...] com conhecimentos sólidos e atualizados em História, e com domínio tanto dos seus aspectos conceituais como dos históricos e epistemológicos e também com conhecimento em Educação, de forma a dispor de elementos que lhe garantam o exercício da docência" (PROJETO PEDAGÓGICO DO CURSO DE HISTÓRIA, 2010, p. 54).

Ainda de acordo com o Projeto Pedagógico, o curso de História pretende atender uma proposta de formação integral do profissional, para além da separação das habilitações licenciatura e bacharelado, pois, ensino e pesquisa são complementares:

É necessária uma formação que não dissocie ensino e pesquisa e forme o historiador como profissional capaz de atuar em todos os campos profissionais onde se exija a construção do conhecimento histórico - aí incluído o magistério e a articulação entre os diferentes níveis de ensino, de modo a garantir a necessária adequação da formação do professor (Idem, 2010, p. 28).

O curso adota regime semestral, ofertado em período noturno. Com relação à carga horária, o estágio supervisionado é uma atividade acadêmica obrigatória na matriz curricular do curso de História, atendendo aos pressupostos da Lei n. ${ }^{\circ} 11.788$, que dispõe sobre o estágio de estudantes (2008), bem como da Decisão Normativa n. ${ }^{\circ} 78$, que aprova a Norma Interna de Estágio Curricular Supervisionado do Curso de Graduação em História - Licenciatura da Universidade (2017).

O estágio supervisionado é componente teórico-prático da formação profissional docente, o qual possibilita ao aluno estagiário participar e compreender o papel social do 
processo educativo. De acordo com o Projeto Pedagógico do referido curso de História: “O estágio é uma oportunidade que o profissional em formação tem para assumir criticamente a sua profissão, o que implica uma inserção política que viabilize a contextualização cultural do meio onde o aluno desenvolve o seu conhecimento prático" (PROJETO PEDAGÓGICO DO CURSO DE HISTÓRIA, 2010, p. 85).

O estágio supervisionado em História acontece nos quatro últimos períodos do curso - V, VI, VII e VIII períodos. Compreende uma carga horária de 15 horas-aula semestrais, e compõe-se de atividades curriculares e extracurriculares. Tendo em vista a atuação do estagiário nas várias modalidades de ensino da educação básica, no que concerne à observação e à regência, o estágio é realizado nas séries finais do ensino fundamental (V e VI períodos) e no ensino médio (VII e VIII períodos).

No que tange à estruturação do estágio supervisionado, o estagiário possui acompanhamento do profissional supervisor, bem como do professor orientador. É denominado de profissional supervisor o docente da escola onde se efetivará o estágio, o qual tem como principal função orientar o licenciando “[...] sobre atividades de planejamento, execução, acompanhamento e avaliação do processo ensinoaprendizagem"; o professor orientador é o docente do curso de licenciatura que ministra a disciplina Estágio Curricular Supervisionado, cuja finalidade é “[...] orientar e esclarecer o aluno estagiário quanto ao seu programa de estágio, colaborando com o seu planejamento, assessorando, acompanhando e avaliando o desenvolvimento do Estágio Curricular Supervisionado" (DECISÃO NORMATIVA, 2017, p. 4).

Com relação ao aspecto metodológico, consta na Decisão Normativa que cabe ao estagiário compreender a escola, em um contexto macro, a partir das políticas públicas educacionais (internacionais, nacionais e locais), estabelecendo relações entre o ambiente escolar e a comunidade; e em um contexto micro, a partir do conhecimento dos documentos que a compõem (por exemplo, o Projeto Político Pedagógico¹) e dos seus espaços físicos. Além disso, consta ser relevante compreender a sala de aula enquanto local específico de conhecimento e de relacionamento entre os diferentes sujeitos (DECISÃO NORMATIVA, 2017, p. 6).

\footnotetext{
1 O Projeto Político Pedagógico é um documento escolar que traz a proposta educacional da instituição de ensino, contendo os objetivos, métodos, diretrizes e metas da mesma.
} 
Ao fim dos quatro últimos semestres do curso de História, o graduando precisa apresentar um relatório escrito, trabalho de conclusão das disciplinas de Estágio Curricular Supervisionado. Documento de caráter formal e científico, o relatório constitui uma atividade de reflexão do aluno estagiário sobre a experiência no estágio, contém o registro das observações, bem como das vivências com a regência. Portanto, o relatório se apresenta como uma atividade reflexiva sobre as ações pedagógicas, ancorada em leituras que trazem pesquisas historiográficas que possibilitam o diálogo entre teoria e prática do ensino de História.

Neste artigo, investigaram-se 12 relatórios de estágio, documentos produzidos por alunos de um curso de licenciatura em História do sétimo período, os quais realizaram a disciplina Orientação e Estágio Curricular Supervisionado III no primeiro semestre de 2019. Tais graduandos estagiaram em escolas públicas de ensino médio. Aqui, para melhor compreensão, os registros dos alunos estagiários serão acompanhados pelas siglas R1, R2, R3... até R12. A partir do universo do relatório de estágio, o presente artigo irá privilegiar, de modo específico, informações concernentes à autoavaliação e às experiências com a observação e com a regência, na medida em que se busca compreender como ocorre a percepção do estagiário sobre suas práticas pedagógicas enquanto futuro professor de História.

\section{Percepções de futuros professores acerca do Estágio Supervisionado em História: experiências e autoavaliação}

No âmbito de realização do estágio, a autoavaliação do estagiário constitui ferramenta eficaz no que diz respeito à autodescoberta docente, a partir de uma análise sobre seu desempenho. Segundo Cosme (2009, p. 105): “[...] a reflexão dos professores constitui, hoje, uma condição necessária à afirmação da profissionalidade docente em função da qual se torna possível a afirmação de projetos sujeitos a uma racionalidade pedagógica democrática".

Isto posto, a autoavaliação se configura como componente da avaliação formativa, perpassando um conjunto de ações cujo objetivo é a melhoria da aprendizagem do aluno estagiário. A autoavaliação: "Refere-se ao processo pelo qual o próprio aluno analisa continuamente as atividades desenvolvidas e em desenvolvimento, registra suas 
percepções e seus sentimentos e identifica futuras ações, para que haja avanço na aprendizagem" (VILLAS BOAS, 2009, p. 51).

Quanto ao objeto de investigação do presente artigo — os 12 relatórios de estágio produzidos pelos graduandos —, foram unânimes ao avaliarem, de modo geral, suas experiências de forma positiva. Isto pode ser notado, por exemplo, no seguinte comentário de R"6: "As aulas de observação contribuíram na percepção das particularidades da educação para jovens e adultos e do ensino noturno.".

Igualmente pode ser constatado sobre ato de ministrar aula: "A regência foi importante para minha experiência profissional, pois me mostrou os desafios que irei enfrentar como futuro professor." (R8).

Parte dos graduandos destacam o estágio como um momento para se fazer a conexão entre teoria e prática, no que tange aos seguintes âmbitos: métodos no processo ensino-aprendizagem, isto é, "A experiência de estágio, além de ter sido gratificante de maneira pessoal para promover a proximidade com o ambiente escolar, foi profissionalmente relevante ao motivar meu contato com estratégias de ensino diferentes e mesmo interdisciplinares." (R11); relações interpessoais proporcionadas, porque "O estágio foi uma ótima oportunidade vivenciar observando e logo em seguida aplicando aulas para as turmas observadas. Isso é bom, pois não perdemos o contato com a sala, e criamos um vínculo maior com os estudantes que observamos." (R2); compreensão do cotidiano profissional docente, pois, "O estágio trouxe uma ampliação da visão acerca do que é ser professor, dos grandes desafios a serem enfrentados quando me tornar docente e me inserir no mercado de trabalho." (R5).

A partir de tais relatos, percebe-se que os graduandos visualizam o estágio como necessário para a formação docente, sobretudo, por proporcionar-lhes o conhecimento da realidade na qual intervirão posteriormente. Como apontam Bellochio e Beineke (2007, p. 75), o estágio supervisionado “[...] deve ser tomado como um momento de produção reflexiva de conhecimentos, em que a ação é problematizada e refletida no contexto presente e, após sua realização, momento este que envolve a discussão com a orientação do estágio e pares da área.".

Uma autorreflexão mais crítica acerca da regência pode ser destacada a seguir, quando o estagiário analisa comparativamente a duas aulas por ele ministradas: 


\begin{abstract}
A primeira regência me fez sentir uma insegurança nunca experimentada antes, pela primeira vez me senti perdido, foi uma experiência ruim, constrangedora e pretendo usá-la como exemplo e motivação para os futuros desafios. Já a segunda regência, vou guardar boas lembranças, quando me senti de fato um professor, quando consegui transmitir aos alunos o conteúdo proposto de forma natural e tranquila. (R3).
\end{abstract}

Isto permite deduzir alguns aspectos que poderiam ter influenciado de forma negativa a experiência com a primeira regência: o receio de não conseguir ministrar uma aula eficaz, a insegurança por não ter domínio em sala de aula, a preocupação em saber todo o conteúdo histórico que se julga necessário, a incerteza acerca do método e/ou da estratégia de aprendizagem a ser utilizada. Diferentemente da primeira, a segunda regência foi avaliada pelo estagiário de forma positiva, o que permite inferir possíveis mudanças, como, por exemplo, maior planejamento sobre as atividades, leitura de produções historiográficas, estudo das metodologias de ensino, discussões e trocas de experiência em sala de aula, conversas com o professor supervisor e com o professor orientador. No trecho, percebe-se ainda a própria tomada de consciência do graduando, por meio do pensamento crítico sobre as dificuldades que precisam ser superadas para um bom trabalho em sala de aula.

No que se refere à atuação dos alunos estagiários na observação do ambiente escolar, as condições de infraestrutura foram lembradas em alguns relatórios. O relato a seguir traz a informação de que a escola onde foi realizada o estágio carece de reforma, porque "[...] se trata de uma construção antiga, castigada pelo tempo e que necessita urgentemente de investimentos por parte do governo estadual." (R4). Em outro relatório, o espaço físico aparece, ao lado de outros fatores, como uma situação complicadora: "Entre os problemas detectados na escola, estão a evasão escolar, a desigualdade social, a segurança, a falta de estrutura e a falta de investimentos do governo." (R3).

Tais relatos chamam atenção para um ponto em comum: a questão dos montantes financeiros aplicados na educação. Conforme assinalam Libâneo, Oliveira e Toschi (2012), o aumento dos recursos públicos destinados à esfera educacional é imprescindível para o enfrentamento dos problemas da educação, porém, por si só, não é suficiente:

A ampliação do investimento público em educação poderá ser pouco eficaz se não houver controle rigoroso sobre a rubrica "gastos com educação", pois estados e municípios costumam debitar nessa rubrica despesas que nada têm a ver com educação e ensino. Da mesma forma, com frequência a legislação estabelece 
metas sem que se designe a fonte de recursos e a responsabilidade de cada ente da Federação em seu cumprimento (p. 172).

Neste sentido, um controle rígido sobre os gastos públicos, aliado à criação de políticas educacionais mais eficientes, constituem medidas fundamentais para a superação de problemas da escola pública brasileira.

Não obstante, conforme os dois últimos relatórios citados, se as condições de infraestrutura de algumas escolas são deficitárias, em outras, verifica-se o oposto:

O prédio teve sua pintura renovada em 2017, e em 70\% das salas de aula estão instalados quadros brancos. Nas salas do piso superior foram instalados aparelhos de projeção (datashow) e caixas de som possibilitando aulas com recursos tecnológicos. De modo geral, todas as salas se encontram em perfeitas condições de funcionamento. (R7).

Com efeito, sabe-se que a estrutura física e material das escolas tem impacto direto no aprendizado dos alunos (SOARES, 2006; FRANCO; BONAMINO, 2005). A concepção de infraestrutura escolar abarca uma série de elementos, tais como: itens considerados básicos, ou seja, fornecimento de água tratada, coleta de lixo, mobiliário adequado e limpeza dos ambientes; espaços de apoio didáticos, isto é, biblioteca, laboratórios de informática e de ciências, quadra de esportes; materiais e recursos didáticos, como livro didático, computador com acesso à internet, aparelho de som, máquina fotográfica. Assim, uma infraestrutura adequada auxilia o desenvolvimento pedagógico do professor, por favorecer condições de trabalho, além de ampliar a possibilidade de aprendizagem do aluno.

Se, de modo geral, todos os graduandos registraram nos relatórios de estágio suas experiências como positivas, de modo específico, um graduando relatou certa dificuldade com relação à prática de ensino propriamente dita: “Durante a regência, percebi o quanto é difícil estar no comando de uma sala de aula, as dificuldades que o professor enfrenta ao manter o controle sobre a sala, em manter a disciplina e o interesse dos alunos em aprender o conteúdo." (R7).

Fica subentendido que a dificuldade mencionada pelo graduando está relacionada, em grande parte, à questão da indisciplina escolar, que, segundo ele, pode dificultar a realização do processo de ensino-aprendizagem, por ser um fenômeno ligado ao descumprimento de regras da instituição de ensino. Isto foi pontuado por Vasconcellos (2004, p. 13): 


\begin{abstract}
Pesquisas pedagógicas mostram o quanto se perde tempo em sala de aula com questões de disciplina, em detrimento da interação dos alunos com o conhecimento e com a realidade, pois está cada vez mais difícil trabalharmos os conteúdos escolares em sala, visando à produção de conhecimento, pois os alunos acabam se distraindo, atrapalham-se com conversas e barulhos, prejudicando sua aprendizagem.
\end{abstract}

É válido salientar que a indisciplina escolar pode estar associada a diversas causas, tanto internas quanto externas à escola, como a situação socioeconômica do discente, a conjuntura familiar, a estrutura da escola, o relacionamento entre professor e aluno, a concepção do professor sobre o processo de ensino-aprendizagem. Assim, é indispensável compreender o(s) fatore(s) gerador(es) da indisciplina escolar, considerando possíveis enfrentamentos.

Em outro relatório, a despeito de algumas ações tomadas pelos professores regentes, a indisciplina permanece no cotidiano das aulas: "Apesar dos esforços dos docentes $A$ e $B^{2}$, a indisciplina é um problema sério a ser corrigido, esta conduta contribui negativamente para o aprendizado dos alunos, além de mexer com o psicológico dos professores." (R4). Ainda que o trecho não diga quais as atitudes tomadas pelos professores para se acabar com a indisciplina, ressalta-se a importância de intervenções conjuntas, em que os principais atores envolvidos - professor e aluno - cheguem a consenso para resolução do conflito. Quando a mesma citação diz: “[...] além de mexer com o psicológico dos professores", subentende que a indisciplina no ambiente escolar pode trazer prejuízos aos docentes, os quais, por vezes, devido às dificuldades de lidar com questões conflitantes em sala de aula, ficam não apenas estressados com seu trabalho, como desgostosos de sua profissão.

Nesse sentido, uma vez detectada a causa da indisciplina escolar, é necessária a busca pela resolução do problema, mediante reflexões coletivas sobre o tema, e de diretrizes políticas educativas de prevenção, em parceria com as comunidades interna e externa.

O fenômeno da indisciplina escolar aparece em um relatório como resultado da falta de concentração dos alunos em sala: "Pude observar a deficiência de foco dos alunos, os alunos desrespeitam o professor, na maioria das vezes com conversas aleatórias durante a aula." (R2). A desatenção citada pode estar relacionada à falta de motivação dos

\footnotetext{
${ }^{2}$ Aqui, os nomes dos professores citados originalmente no relatório foram ocultados.
} 
educandos, pois, ao se interessarem pelos conteúdos escolares abordados, participam ativamente dos debates em sala de aula, adquirindo também novos saberes.

Isso também pode ser constatado no relatório a seguir, em se tratando do ensino de história:

[...] em muitas situações presenciei os alunos desinteressados pela disciplina, por não conseguirem atribuir significado aos temas das aulas, o que, pela minha análise, aconteceu porque eles não compreendiam como as fontes foram utilizadas para interpretar o passado, e consequentemente, transformar uma história vivida nos conteúdos que eram objetos das aulas. (R1).

No relatório anterior, a não atribuição de significado pelos alunos pode resultar da falta de habilidade em realizar a interpretação histórica. De acordo com Rüsen (2007), o trabalho com o conhecimento histórico nas escolas é essencial para a formação da consciência histórica, de modo que os alunos atribuam significado às suas experiências temporais individuais e coletivas, orientando-se no tempo. Assim, a aprendizagem histórica precisa considerar a experiência do sujeito que aprende, capacitando-o para elaboração de uma narrativa histórica: aprender história significa aprender a narrá-la.

A formação histórica é, antes, a capacidade de uma determinada constituição narrativa de sentido. Sua qualidade específica consiste em (re)elaborar continuamente, e sempre de novo, as experiências correntes que a vida prática faz do passar do tempo, elevando-as ao nível cognitivo da ciência da história, e inserindo-as continuamente, e sempre de novo, na orientação histórica dessa mesma vida (RÜSEN, 2007, p. 104).

Em outro relatório de estágio é destacada a questão do desprestígio da disciplina História, que aparece como um empecilho para a apropriação de conhecimentos históricos pelos alunos: "Boa parte dos alunos não entendem o motivo de ter que estudar a disciplina história, e acreditam que as únicas disciplinas que serão úteis em sua vida serão as disciplinas de português e matemática" (R7). Com efeito, percebe-se, por vezes, uma desvalorização da disciplina História em relação a outras disciplinas consideradas mais "importantes", do ponto de vista "científico". Tal desprestígio pode ser explicado por uma série de fatores, como: a não valorização, no Brasil, do passado e dos chamados lugares de memória (museus, monumentos, praças, arquivos, etc.); a baixa carga horária da disciplina História na grade curricular da educação básica³ , dentre outros.

\footnotetext{
3 Em média, a grade curricular da disciplina História é um terço das disciplinas de Língua Portuguesa e Matemática, consideradas referências nas matrizes curriculares. Tal falta de notoriedade pode ser percebida principalmente no documento normativo para elaboração de currículos, a Base Nacional Comum Curricular, que secundariza, nas modalidades do Ensino Fundamental II e do Ensino Médio, também as disciplinas Geografia, Artes, Filosofia e Sociologia.
} 
Assim, o desinteresse do aluno pode influenciar o rendimento escolar, inviabilizando o processo de ensino e aprendizagem. Uma vez percebido o que poderia ser problemático, o estagiário traz a ação tomada no momento da sua regência: “[...] procurei em todas as aulas ministradas, tentar despertar a atenção dos alunos para que os mesmos desenvolvessem um pensamento crítico." (R12).

É necessário frisar que o conhecimento histórico ensino precisa atender a interesses comuns, partindo da vida cotidiana dos alunos, tendo como função a orientação da vida prática. Isto fica claro no relato a seguir, quando o estagiário, ao ministrar aula sobre o patrimônio histórico-cultural, parte do âmbito da regionalidade para construir, nos alunos, o sentimento de pertencimento a uma cultura: "Para ensinar a história dos modos de vida e das manifestações culturais, nada melhor que recorrer a exemplos da região onde a escola se insere, de modo a tomar o ensino mais próximo das vivências dos alunos, e, portanto, mais compreensível para eles." (R7).

Segundo o relato, a aula se iniciou com um questionamento a respeito do que os alunos consideravam patrimônio no município onde se localiza a escola. Partiu-se de uma discussão inicial sobre o conceito de patrimônio cultural, e as diferenças entre patrimônio material e imaterial na cidade, bem como da apresentação de imagens que retrataram esses patrimônios: "Os alunos ficaram empolgados, fazendo perguntas e citando os patrimônios que eles conheciam. Uma parte dos alunos tinham visitado os patrimônios históricos mostrados em sala de aula, mas não tinham ideia que aquele local era um patrimônio do município." (R7). Aqui, percebe-se a descoberta do conhecimento histórico a partir da construção de conceitos que estão presentes no cotidiano dos alunos, envolvendo, por exemplo, noções de tempo, e relações entre permanência e transformação. Além disto, evidencia-se que esse trabalho possibilita ao aluno compreender a importância da preservação da memória por meio da conservação do patrimônio regional.

Em outro relatório, a preocupação em priorizar o aluno como construtor do seu conhecimento também fica evidenciada. Ao abordar a temática A África para além do olhar branco, o estagiário, em quatro aulas por ele ministradas, teve como objetivo "[...] desconstruir algumas visões estabelecidas sobre as antigas sociedades africanas e dar um olhar afrocentrado para a abordagem historiográfica." (R10). Quando indagados sobre o que conheciam do continente africano, os alunos "[...] foram unânimes entre selva, 
escravidão, negros, animais, tribos", respostas que o motivaram "[...] a descortinar os olhares." (R10).

Conforme o relatório, em um primeiro momento, foram trabalhados conceitos básicos, como “[...] eurocentrismo, pan africanismo, afrocentricidade e colonização, buscando levar os alunos à reflexão sobre o modo como várias visões foram se constituindo sobre África, mas sempre com o olhar colonizador sobre a mesma." (R10). Após a discussão desses conceitos, exibiu-se um pequeno vídeo sobre a importância de se considerar várias construções historiográficas, e não uma "história única”, e, em seguida, tratou-se sobre as perspectivas gerais dos povos bantos, enfatizando o Reino do Congo. Tal abordagem teve por finalidade "[...] aproximar a realidade das sociedades africanas com algumas manifestações culturais, linguísticas e religiosas brasileiras." (R10).

Segundo o mesmo relatório, "[...] o feedback dos alunos foi bastante positivo", posto que se envolveram com o tema, mostrando-se curiosos. Nesse contexto, verifica-se a importância de desenvolver, no aluno, competências de interpretação e compreensão do passado, por meio da interiorização de novas qualidades cognitivas. No entendimento de Rüsen (2007, p. 104): “Aprender é a elaboração da experiência na competência interpretativa e ativa, e a formação histórica nada mais é do que uma capacidade de aprendizado especialmente desenvolvida."

Portanto, entende-se o estágio como atividade de ação-reflexão-ação crítica sobre as práticas pedagógicas, as quais são experienciadas pelo professor em sua formação inicial. No estágio supervisionado em História, é uma oportunidade para o graduando compreender como ocorre a aprendizagem histórica na escola, para possibilitar aos alunos um melhor entendimento de sua vida cotidiana.

\section{CONSIDERAÇÕES FINAIS}

O estágio supervisionado é um importante momento para o graduando refletir acerca de sua formação, bem como sobre os desafios e as possibilidades da profissão docente. A análise dos relatórios de estágio dos graduandos em História neste estudo permitiu visualizar suas autorreflexões, a partir de uma melhor compreensão de si próprios como futuros professores/historiadores. 
Segundo os relatórios, a experiência com a observação do ambiente escolar permitiu aos graduandos compreender a complexidade deste espaço de pluralidade, problemático e desafiador. Tal evidenciou as dificuldades que o professor pode encontrar ao ministrar suas aulas, tendo em vista a questão da indisciplina, do desinteresse e da desmotivação por parte do aluno.

Com relação à regência da disciplina, é fundamental que os cursos de Licenciatura em História possibilitem ao futuro professor/historiador compreender não apenas os conhecimentos históricos sistematizados pela historiografia, mas também a forma como são apropriados no aprendizado de História pelos alunos. Isto se nota em dois relatórios de estágio sobre a experiência com a regência, nos quais, para além da memorização de eventos e fatos de forma mecanizada, valorizou-se a construção do conhecimento histórico pelo aluno.

Nesse sentido, percebe-se o estágio supervisionado em História como fenômeno que promove a unidade entre a teoria e a prática, possibilitando ao futuro professor/historiador pensar, questionar e enfrentar situações novas colocadas para a profissão.

Os resultados mostram que $\mathrm{O}$ estágio possibilitou aos futuros professores/historiadores compreender o cotidiano escolar, refletir sobre o diálogo entre os conhecimentos históricos sistematizados pela historiografia e o processo do aprender a pensar historicamente, além de realizar intervenções que contribuíram para um ensino de História voltado à orientação prática da vida dos alunos.

\section{REFERÊNCIAS}

BELLOCHIO, C. R.; BEINEKE, V. A. Mobilização de conhecimentos práticos no estágio supervisionado: um estudo com estagiários de música da UFSM/RS e da UDESC/SC. Música Hodie, Goiânia, v. 7, n. 2, 2007, p. 73-88.

BRASIL. Lei $n^{\circ} 11.788$, de 25 de setembro de 2008. Dispõe sobre o estágio de estudantes; altera a redação do art. 428 da Consolidação das Leis do Trabalho - CLT, aprovada pelo Decreto-Lei no 5.452, de 10 de maio de 1943, e a Lei no 9.394, de 20 de dezembro de 1996; revoga as Leis nos 6.494, de 7 de dezembro de 1977, e 8.859, de 23 de março de 1994, o parágrafo único do art. 82 da Lei no 9.394, de 20 de dezembro de 1996, e o art. 60 da Medida Provisória no 2.164-41, de 24 de agosto de 2001; e dá outras providências. Diário Oficial da União: seção 1, Brasília, DF, p. 3, 26 set. 2008. Disponível em: 
http://www.planalto.gov.br/ccivil_03/_ato2007-2010/2008/lei//11788.htm. Acesso em: 14 jun. 2021.

CAVALCANTI, L. de S. A formação do professor de geografia - o lugar da prática de ensino. In: TIBALLI, Elianda Figueiredo Arantes; CHAVES, Sandramara Matias. Concepções e práticas em formação de professores diferentes olhares. Rio de Janeiro: DP\&A, 2003.

CORSETTI, B.; CANAN, S. R. A formação docente na área de História: reflexões a partir da análise das diretrizes curriculares para a formação de professores da educação básica. In: BARROSO, V. L. M. et al. Ensino de história: desafios contemporâneos. Porto Alegre: ANPUH-RS/EST/Exclamação, 2010. p. 41-55.

COSME, A. Ser professor: a ação docente como uma ação de interlocução qualificada. Porto: Livpsic, 2009.

FÁVERO, Maria de Lourdes Albuquerque. Universidade e estágio curricular: subsídios para discussão. In: ALVES, Nida. Formação de professores - pensar e fazer. 11. ed. São Paulo: Cortez, 2011.

FRANCO, C.; BONAMINO, A. A pesquisa sobre característica de escolas eficazes no Brasil: breve revisão dos principais achados e alguns problemas em aberto. Revista do Programa de Pós Graduação em PUC-Rio, Rio de Janeiro, n. 1, 2005, p. 2-13.

LIBÂNEO, J. C.; OLIVEIRA, J. F. de; TOSCHI, M. S. Educação escolar: políticas públicas, estrutura e organização. São Paulo: Cortez, 2012.

PIMENTA, S. G.; LIMA, M. S. L. Estágio e docência. 8. ed. São Paulo: Cortez, 2017.

RÜSEN, J. Didática da história: passado, presente e perspectivas a partir do caso alemão. Trad. Marcos Roberto Kusnick. Práxis Educativa, Ponta Grossa, v. 1, n. 2, jul./dez. 2006. p. 07-16.

RÜSEN, J. História viva: teoria da história: formas e funções do conhecimento histórico. Trad. Estevão de Rezende Martins. Brasília: Editora UNB, 2007.

SOARES, J. F.; ANDRADE, R. Nível socioeconômico, qualidade e equidade das escolas de Belo Horizonte. Ensaio: aval. pol. públ. Educ., Rio de Janeiro, v. 14, n. 50, 2006.

UNIVERSIDADE FEDERAL DO TRIÂNGULO MINEIRO. Projeto pedagógico do curso de história, 2010.

UNIVERSIDADE FEDERAL DO TRIÂNGULO MINEIRO. Decisão Normativa n. 78, de 12 de dezembro de 2017, do Conselho de Ensino. Aprova Norma Interna de Estágio Curricular Supervisionado do Curso de Graduação - Licenciatura da Universidade. Uberaba, UFTM, 2017. 
VASCONCELOS, C. S. Indisciplina e disciplina escolar: fundamentos para o trabalho docente. São Paulo: Cortez, 2014.

VILLAS BOAS, B. M. de F. Virando a escola do avesso por meio da avaliação. Campinas: Papirus, 2009.

Recebido em: 20/06/2020

Parecer em: 13/04/2021 Aprovado em: 25/05/2021 